\title{
Valor nutricional do milho termicamente processado, usado na ração pré-inicial para frangos de corte
}

[Nutritional value of heat processed corn in formulating broiler pre-starter diet]

\author{
E.R. Freitas ${ }^{1}$, N.K. Sakomura ${ }^{2}$, R. Neme ${ }^{3}$, N.A.A. Barbosa ${ }^{4}$ \\ ${ }^{1}$ Departamento de Zootecnia - Centro de Ciências Agrárias - Universidade Federal do Ceará \\ Campus do Pici - Caixa Postal 12.168 \\ 60355-970 - Fortaleza, CE \\ ${ }^{2}$ Departamento de Zootecnia - FCAV - UNESP - Jaboticabal, SP \\ ${ }^{3}$ Aluno de pós-graduação - FCAV - UNESP - Jaboticabal, SP \\ ${ }^{4}$ Aluno de graduação - FCAV - UNESP - Jaboticabal, SP
}

\begin{abstract}
RESUMO
Foram conduzidos um ensaio de metabolismo para determinar o valor nutricional do milho termicamente processado (MP) e não-processado (MNP) e outro de desempenho para comparar o uso desses alimentos em dietas pré-iniciais para frangos de corte. Não foram observadas diferenças entre a digestibilidade da matéria seca (MS), do extrato etéreo, da proteína bruta e do amido e valores de energia metabolizável aparente dos tipos de milho avaliados. A energia metabolizável aparente corrigida do MP (3.537kcal $/ \mathrm{kg}$ de MS) foi maior $(\mathrm{P}<0,05)$ que a determinada para o MNP $(3.411 \mathrm{kcal} / \mathrm{kg}$ de $\mathrm{MS})$. No ensaio de desempenho, os tratamentos foram: T1 - dieta formulada com MNP; T2 - dieta formulada com MP; e T3 dieta T1, com substituição isométrica do MNP por MP. Na primeira semana, as aves alimentadas com MP (T2) apresentaram maior consumo $(\mathrm{P}<0,05)$ e pior conversão $(\mathrm{P}<0,05)$ em relação às alimentadas com MNP (T1). A substituição isométrica do MNP por MP não influenciou no desempenho das aves. No período de 1 a 42 dias, os tratamentos não influenciaram o desempenho dos frangos.
\end{abstract}

Palavras-chave: frango, alimentação pré-inicial, energia metabolizável, milho gelatinizado

\begin{abstract}
A digestibility trial was carried out to evaluate the nutrient digestibility of heat-processed corn (PC) and not processed corn (NPC). A trial was also carried out to evaluate the effect of PC and NPC in prestarter diet on broiler performance from 1 to 42 days of age. The dry matter (DM), ether extract, crude protein and starch digestibilities and apparent metabolizable energy for $P C$ were similar $(P>0.05)$ to those observed for NPC. The corrected apparent metabolizable energy of PC $(3,537 \mathrm{kcal} / \mathrm{kg}$ of DM) was higher than NPC $(3,411 \mathrm{kcal} / \mathrm{kg}$ of DM). The treatments in the performance trial were T1-diet formulated with NPC, T2- diet formulated with PC, and T3 - isometric substitution of NPC for PC in T1 diet. The broiler fed on NRC diets showed lower feed consumption and weight gain:feed consumption ratio from 1 to 7 days of age than broiler fed on PC diets. The isometric substitution of NPC for PC in the pre-starter diet did not affect the performance of birds. No treatment effect on broiler performance from 1 to 42 days of age was also observed.
\end{abstract}

Keywords: broiler, gelatinized corn, metabolizable energy, pre-starter feeding

Recebido para publicação em 1 de dezembro de 2003

Recebido para publicação, após modificações, em 9 de junho de 2004

E-mail: ednardo@ufc.br 


\section{INTRODUÇÃO}

As limitações fisiológicas para o aproveitamento de nutrientes nos primeiros dias de vida dos pintos e a importância desse período para o sucesso no desempenho dos frangos de corte têm levado a estudos sobre o uso de dietas especiais para a primeira semana de vida. Vieira e Pophal (2000) e Penz (2001) recomendaram que as rações pré-iniciais devem ser formuladas com ingredientes de melhor qualidade, podendo ainda ser processadas por extrusão ou peletização (Penz, 2001).

Como as características dos grãos de cereais utilizados nas rações das aves podem interferir na capacidade de utilização dos nutrientes desses alimentos nos primeiros dias de vida dos pintos, o maior potencial de gelatinização do amido presente nos grãos de cereais é uma característica desejável, pois espera-se que melhore a digestibilidade dos grãos (Vieira e Pophal, 2000).

O milho é considerado o mais importante componente energético das rações. Se corretamente processado pelo calor, a digestibilidade de seus nutrientes é melhorada, principalmente a da energia (Moreira et al., 1994). O tratamento térmico aumenta a digestibilidade dos carboidratos porque a amilose e a amilopectina, organizadas inicialmente em grânulos, são expostas a uma maior ação enzimática quando os grânulos são desfeitos pelo calor. Processos que utilizam temperatura e pressão com potencial para a gelatinização do amido aumentam a digestibilidade que resulta em maiores valores de energia metabolizável. Também, melhoram a digestibilidade dos lipídios presentes nos grãos, pelo rompimento das estruturas celulares que os protegem (Leeson e Summers, 1997).

Os valores de energia metabolizável dos alimentos podem ser menores nos primeiros dias de vida das aves em conseqüência das limitações fisiológicas para o aproveitamento de nutrientes nessa fase. Segundo Nir (1998), os valores de energia metabolizável aparente corrigida (EMAn) encontrados nas tabelas de composição dos alimentos estão acima dos valores corretos para pintos na primeira semana, e essa diferença deve ser considerada na formulação das rações.
Os objetivos deste estudo foram determinar o valor nutricional do milho termicamente processado (MP) comparado ao do nãoprocessado (MNP) para pintos de corte na primeira semana de vida e comparar o uso do MP em relação ao MNP em rações pré-iniciais formuladas com os valores de EMAn determinados sobre o desempenho de frangos de corte.

\section{MATERIAL E MÉTODOS}

Foram conduzidos um ensaio de metabolismo e outro de desempenho utilizando-se milho retirado de um mesmo lote, sendo uma parte submetida ao processamento térmico. $\mathrm{O}$ processamento do milho foi realizado pela empresa que comercializa esse produto, utilizando o sistema de pré-cozimento de cereais. Durante o processamento, os grãos, limpos, são encaminhados para o reator, para serem submetidos ao vácuo ( $3 \mathrm{~min}$ ), para a retirada do oxigênio, e ao aquecimento $\left(63\right.$ a $\left.107^{\circ} \mathrm{C}\right)$, para expô-los ao vapor direto (8 a $12 \mathrm{~min})$. Após atingir a temperatura máxima, o aquecimento é mantido (cozimento) com vapor indireto (15 a 18 min). Depois do cozimento, ainda no reator, inicia-se o resfriamento com aplicação de vácuo (13 a 15 min). Os grãos, ao saírem do reator com temperatura variando entre 65 e $70^{\circ} \mathrm{C}$, são submetidos ao resfriamento final após o que apresentam temperatura $5^{\circ} \mathrm{C}$ acima da temperatura ambiente com $12 \%$ de umidade.

Amostras dos alimentos foram levadas ao laboratório para a determinação de matéria seca, proteína bruta, extrato etéreo, matéria mineral e fibra bruta (Silva, 1990) e de energia bruta e amido. A energia bruta foi determinada em bomba calorimétrica adiabática ${ }^{1}$, e o amido de acordo com a metodologia enzimática modificada para leitura de glicose por colorimetria $^{2}$, segundo Pereira e Rossi (1995). A enzima utilizada para a hidrólise do amido foi a amiloglicosidase, na concentração de $6.100 \mathrm{unid} / \mathrm{ml}$. O critério adotado para o aproveitamento dos resultados das análises foi a taxa de recuperação do amido, usando-se uma reta-padrão. Quando a taxa de recuperação foi

\footnotetext{
${ }^{1}$ Modelo MS 10 A, Ralph \& Partner, Alemanha

2 Kit enzimático Glicose Enz Color-Standard (A-3042, Sigma,USA)
} 


\section{Freitas et al.}

superior a $90 \%$, os resultados foram aproveitados, caso contrário, as amostras foram submetidas à nova determinação.

Para o controle de qualidade do processamento do milho, usou-se o índice de absorção de água, obtido de acordo com a técnica proposta por Holay e Harper (1982). Os coeficientes de digestibilidade e os valores de energia metabolizável aparente (EMA) e EMAn foram determinados em ensaio de metabolismo, pelo método da coleta total de excretas.

Foram utilizados 180 pintos de corte, machos de um dia Cobb. As aves foram alojadas em baterias com aquecimento e distribuídas ao acaso, em três tratamentos e seis repetições de 10 aves por repetição. Nas rações-teste, os alimentos substituíram, com base na matéria natural, 40\% da ração de referência (Tab. 1).

Tabela 1. Composição percentual e calculada da ração de referência e das dietas experimentais para aves de 1 a 7 dias

\begin{tabular}{|c|c|c|c|c|}
\hline \multirow{2}{*}{ Ingrediente } & \multirow{2}{*}{ Ração-referência } & \multicolumn{3}{|c|}{ Ração experimental } \\
\hline & & T1 & $\mathrm{T} 2$ & T3 \\
\hline Milho não-processado (comum) & 61,755 & 54,982 & -- & -- \\
\hline Milho processado (gelatinizado) & -- & -- & 56,250 & 54,982 \\
\hline Farelo de soja & 34,139 & 36,363 & 36,118 & 36,363 \\
\hline Óleo de soja & -- & 4,533 & 3,507 & 4,533 \\
\hline Calcário & 1,064 & 1,069 & 1,072 & 1,069 \\
\hline Fosfato bicálcico & 1,815 & 1,854 & 1,851 & 1,854 \\
\hline Mistura mineral $^{1}$ & 0,050 & 0,050 & 0,050 & 0,050 \\
\hline Mistura vitamínica $^{2}$ & 0,300 & 0,300 & 0,300 & 0,300 \\
\hline $\mathrm{L}-$ lisina $\mathrm{HCl}$ & 0,204 & 0,172 & 0,176 & 0,172 \\
\hline DL - metionina $99 \%$ & 0,235 & 0,248 & 0,247 & 0,248 \\
\hline Sal comum & 0,438 & 0,429 & 0,429 & 0,429 \\
\hline Total & 100,00 & 100,00 & 100,00 & 100,00 \\
\hline \multicolumn{5}{|l|}{ Composição calculada } \\
\hline EMAn kcal/kg & 2.875 & 2.900 & 2.900 & 2.900 \\
\hline Proteína bruta (\%) & 21,172 & 21,543 & 21,543 & 21,543 \\
\hline Lisina $(\%)$ & 1,263 & 1,283 & 1,283 & 1,283 \\
\hline Metionina (\%) & 0,490 & 0,575 & 0,575 & 0,575 \\
\hline Metionina + cistina, $(\%)$ & 0,895 & 0,911 & 0,911 & 0,911 \\
\hline Treonina, $(\%)$ & 0,811 & 0,829 & 0,829 & 0,829 \\
\hline Triptofano, $(\%)$ & 0,259 & 0,269 & 0,269 & 0,269 \\
\hline Cálcio, $(\%)$ & 0,955 & 0,971 & 0,971 & 0,971 \\
\hline Fósforo disponível, (\%) & 0,450 & 0,456 & 0,456 & 0,456 \\
\hline Sódio (\%) & 0,216 & 0,212 & 0,212 & 0,212 \\
\hline
\end{tabular}

1- Mistura mineral (quantidade/kg do produto): $\mathrm{Mn}-150.000 \mathrm{mg}, \mathrm{Zn}-100.000 \mathrm{mg}, \mathrm{Fe} 100.000 \mathrm{mg}, \mathrm{Cu}-16.000 \mathrm{mg}$, I - $1.500 \mathrm{mg}$.

2- Mistura vitamínica (quantidade/kg do produto): - vit. A - 2.666.000 UI, vit. B1 - 600mg, vit. B2 - 2.000mg, vit. B6 - 933,10mg, vit. B12 - 4.000mcg, vit. D3 - 666,50mg, vit. E - 5.000 UI, vit. K - 600mg, ácido fólico - 333,25mg, ácido pantotênico - 5.000mg, biotina $-20 \mathrm{mg}$, colina $-133.330 \mathrm{mg}$, niacina $-13.333 \mathrm{mg}$, selênio $-100 \mathrm{mg}$, antioxidante $-7,5 \mathrm{~g}$, coccidiostático $-33,332 \mathrm{~g}$, promotor de crescimento - 20g, veículo QSP - 1000g.

$\mathrm{T} 1=$ ração com milho não processado; $\mathrm{T} 2=$ ração com milho processado; $\mathrm{T} 3=$ ração $\mathrm{T} 1$ com substituição isométrica

EMAn = energia metabolizável aparente corrigida.

O período experimental foi de um a oito dias de idade, sendo os três primeiros dias para adaptação às rações experimentais e os cinco últimos para coleta das excretas. Água e ração foram oferecidas à vontade.

Foram instaladas bandejas de alumínio sob as gaiolas para a realização de duas coletas de excreta por dia, as quais foram congeladas. No final do período experimental, após o descongelamento à temperatura ambiente e homogeneização das excretas de cada repetição, retiraram-se amostras, que foram secas em estufa de ventilação forçada a $55^{\circ} \mathrm{C}$, por 72 horas. Em seguida, foram moídas e levadas ao laboratório, junto com amostras das rações experimentais, para a determinação da matéria seca, do nitrogênio, do extrato etéreo, da energia bruta e do amido, utilizando-se as mesmas metodologias descritas para as análises dos alimentos. 
Com base nos resultados de laboratório, foram calculados os coeficientes de digestibilidade aparente da matéria seca (CDMS), do extrato etéreo (CDEE), da proteína bruta (CDPB) e do amido (CDA) e os valores EMA e EMAn, utilizando as equações propostas por Matterson et al. (1965).

No ensaio de desempenho, foram utilizados 540 pintos de um dia, machos, linhagem Cobb, alojados em um galpão experimental, subdividido em boxes. As aves foram pesadas individualmente e, com base no peso, foram distribuídas entre os tratamentos, para que as parcelas apresentassem peso médio semelhante. $\mathrm{O}$ delineamento experimental utilizado foi inteiramente ao acaso, com três tratamentos e seis repetições de 30 aves por repetição. Os tratamentos foram: $\mathrm{T} 1$ - ração pré-inicial formulada com MNP; T2 - ração pré-inicial formulada com MP; e T3 - ração $\mathrm{T} 1$, com substituição isométrica do MNP por MP.
As rações para cada fase (Tab. 1 e 2) foram formuladas segundo as exigências nutricionais e a composição dos alimentos proposta por Rostagno et al. (2000), com exceção da EMAn dos milhos para os tratamentos T1 e T2. Nessas rações, consideraram-se os valores de EMAn determinados na primeira semana. Após a fase pré-inicial, as aves de todos os tratamentos receberam as mesmas rações até o final do experimento. Durante todo o período experimental, ração e água foram oferecidas à vontade. Em cada fase, as características avaliadas foram: ganho de peso (g/ave), consumo de ração (g/ave) e conversão alimentar.

No interior do galpão registraram-se: temperatura média das máximas igual a $31,4^{\circ} \mathrm{C}$ e das mínimas, $22,7^{\circ} \mathrm{C}$, e unidade relativa média das máximas de 64,8\% e das mínimas, 36,1\%. Registaram-se as mortes para correção dos cálculos do índice de desempenho.

Tabela 2. Composição percentual e calculada das rações experimentais, após a fase pré-inicial, para aves, segundo o período de criação

\begin{tabular}{|c|c|c|c|}
\hline \multirow[b]{2}{*}{ Ingrediente } & \multicolumn{3}{|c|}{ Ração } \\
\hline & $\begin{array}{c}\text { Inicial } \\
(8-21 \text { dias })\end{array}$ & $\begin{array}{c}\text { Engorda } \\
\text { (22-35 dias) }\end{array}$ & $\begin{array}{c}\text { Final } \\
(35-42 \text { dias })\end{array}$ \\
\hline Milho & 59,393 & 61,426 & 62,045 \\
\hline Farelo de soja & 34,298 & 31,336 & 29,501 \\
\hline Óleo de soja & 2,314 & 3,432 & 4,817 \\
\hline Calcário & 1,052 & 1,007 & 0,982 \\
\hline Fosfato bicálcico & 1,780 & 1,650 & 1,553 \\
\hline Mistura mineral $^{1}$ & 0,050 & 0,050 & 0,050 \\
\hline Mistura vitamínica $^{2,3}$ & 0,300 & 0,300 & 0,300 \\
\hline $\mathrm{L}-$ lisina $\mathrm{HCl}$ & 0,144 & 0,181 & 0,177 \\
\hline DL - metionina $99 \%$ & 0,229 & 0,206 & 0,190 \\
\hline Sal comum & 0,440 & 0,411 & 0,386 \\
\hline Total & 100,00 & 100,00 & 100,00 \\
\hline \multicolumn{4}{|l|}{ Composição calculada } \\
\hline EMAn (kcal/kg) & 3.000 & 3.100 & 3.200 \\
\hline Proteína bruta (\%) & 20,940 & 19,786 & 18,989 \\
\hline Lisina $(\%)$ & 1,215 & 1,167 & 1,114 \\
\hline Metionina (\%) & 0,551 & 0,512 & 0,485 \\
\hline Metionina + cistina, $(\%)$ & 0,882 & 0,829 & 0,792 \\
\hline Treonina, $(\%)$ & 0,807 & 0,760 & 0,730 \\
\hline Triptofano, $(\%)$ & 0,259 & 0,241 & 0,229 \\
\hline Cálcio, $(\%)$ & 0,942 & 0,886 & 0,848 \\
\hline Fósforo disponível, (\%) & 0,442 & 0,414 & 0,393 \\
\hline Sódio $(\%)$ & 0,216 & 0,203 & 0,192 \\
\hline \multicolumn{4}{|c|}{ 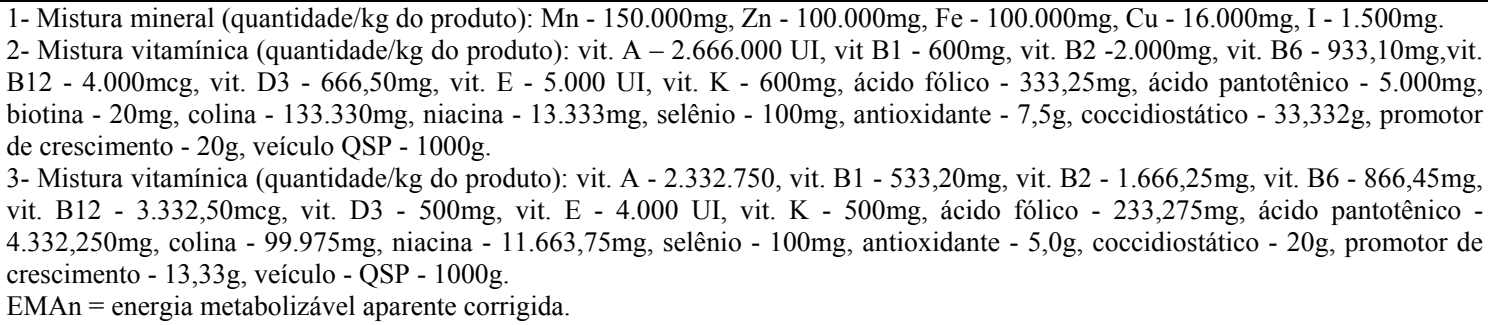 } \\
\hline
\end{tabular}


Os dados do ensaio de metabolismo foram submetidos à análise de variância (User's... 1996) segundo modelo inteiramente ao acaso.

Os dados de desempenho foram submetidos à análise de variância, utilizando-se do procedimento GLM (User's..., 1996). As comparações de médias, por contrastes ortogonais, foram: T1 vs T2 para testar o efeito da substituição do MNP por MP em rações isonutritivas e T1 vs T3 para testar o efeito da substituição isométrica do MNP por MP.

\section{RESULTADOS E DISCUSSÃO}

A composição química e os valores de energia bruta, macro e microminerais dos milhos avaliados, são apresentados nas Tab. 3 e 4, respectivamente. A composição dos alimentos de origem vegetal pode ser influenciada por fatores como: solo, clima e variedade genética. Os tipos de milho estudados apresentaram valores de composição semelhantes aos encontrados na literatura (Tabelas..., 1991; Nutrient..., 1994; Rostagno et al., 2000) para o milho comum.

Tabela 3. Composição bromatológica do milho não-processado e processado

\begin{tabular}{lcc}
\hline Constituinte & $\begin{array}{c}\text { Milho } \\
\text { não-processado }\end{array}$ & $\begin{array}{c}\text { Milho } \\
\text { processado }\end{array}$ \\
\hline Matéria seca (\%) & 88,43 & 88,16 \\
Proteína bruta (\%) & 9,30 & 9,42 \\
Extrato etéreo (\%) & 3,54 & 3,68 \\
Amido (\%) & 75,70 & 77,79 \\
Energia bruta (kcal/kg) & 4453 & 4374 \\
\hline Valores expressos com base na matéria seca.
\end{tabular}

Tabela 4. Composição de macro e microminerais do milho não-processado e processado

\begin{tabular}{lcc}
\hline Constituinte & $\begin{array}{c}\text { Milho } \\
\text { não-processado }\end{array}$ & $\begin{array}{c}\text { Milho } \\
\text { processado }\end{array}$ \\
\hline Cálcio (\%) & 0,12 & 0,12 \\
Fósforo (\%) & 0,25 & 0,24 \\
Potássio (\%) & 0,35 & 0,32 \\
Magnésio (\%) & 0,12 & 0,10 \\
Sódio (\%) & 0,02 & 0,02 \\
\hline
\end{tabular}

Valores expressos com base na matéria seca.
Segundo Moreira et al. (1994 e 2001), o controle de qualidade, isto é, da eficiência do processamento térmico em promover a gelatinização do amido do milho, tem sido realizado pela absorção de água. Quanto maior o índice de absorção de água, maior o grau de gelatinização do amido promovido pelo processamento térmico e melhores são os resultados de utilização dos nutrientes. A absorção média de água obtida para os tipos de milho avaliados nesta pesquisa foi de $369 \%$ e $388 \%$ para o MNP e MP, respectivamente.

Observou-se que o MP absorveu mais água, indicando que o amido deste milho apresentou maior grau de gelatinização que o do MNP. A gelatinização do amido, promovida pelo processamento térmico, pode ser considerada baixa em função do valor de absorção de água obtido. De acordo com Moreira et al. (1994), o grau de gelatinização do amido do milho depende do processo utilizado e, para os processos mais eficientes em promover essa gelatinização, são obtidos índices de $500 \%$ para a absorção de água.

O milho usado neste experimento foi processado inteiro (grão inteiro), enquanto, nas avaliações de Moreira et al. (1994), ele foi moído antes de ser processado. Esse fato certamente influenciou no grau de gelatinização do amido, indicando que o processamento utilizado não foi eficiente.

No ensaio de metabolismo, não foram observadas diferenças significativas $(\mathrm{P}>0,05)$ entre os coeficientes de digestibilidade da matéria seca, do extrato etéreo, da proteína bruta e do amido determinados para MP e MNP. Dessa forma, o processamento utilizado não melhorou significativamente a digestibilidade do milho (Tab. 5).

A análise dos dados de EMA (Tab. 5) mostrou que os valores obtidos para os dois tipos de milho não diferiram entre si $(\mathrm{P}>0,05)$. Entretanto, observou-se que a energia EMAn do MP foi significativamente $(\mathrm{P}<0,05)$ superior à obtida para o MNP. Essa diferença foi da ordem de $126 \mathrm{kcal} / \mathrm{kg}$ de MS. 
Tabela 5. Coeficientes de digestibilidade e valores de energia metabolizável obtidos para o milho processado ou não com pintos de corte na primeira semana

\begin{tabular}{lccc}
\hline Variável & Milho processado & Milho não-processado & Média \\
\hline CDMS (\%) & $82,03 \pm 2,57$ & $81,36 \pm 1,02$ & 81,69 \\
CDPB (\%) & $63,87 \pm 8,19$ & $62,57 \pm 5,50$ & 63,22 \\
CDEE (\%) & $82,87 \pm 3,45$ & $82,46 \pm 2,69$ & 82,67 \\
CDA (\%) & $97,48 \pm 0,50$ & $97,65 \pm 0,14$ & 97,57 \\
EMA (kcal/kg de MS) & $3.637 \pm 111$ & $3.591 \pm 52$ & 3.614 \\
EMAn (kcal/kg de MS) & $3.537 \pm 96 \mathrm{a}$ & $3.411 \pm 46 \mathrm{~b}$ & 3.474 \\
EMAn (kcal/kg de MN) & $3.117 \pm 86 \mathrm{a}$ & $3.016 \pm 41 \mathrm{~b}$ & 3.067 \\
\hline
\end{tabular}

CD (digestibilidade aparente); CDMS (CD- matéria seca); CDPB (CD- proteína bruta); CDEE (CD- estrato etéreo); CDA (CDamido); EMA (energia metabolizável aparente); EMAm (EMA corrigida); $M S=$ matéria seca; $M N=$ matéria natural.

$\mathrm{Na}$ linha, médias seguidas por letras distintas diferem entre si pelo teste $\mathrm{F}(\mathrm{P}<0,05)$.

As variações entre os resultados de EMA e EMAn observadas neste experimento podem ser atribuídas, em parte, às diferenças e às variações no balanço de nitrogênio das aves alimentadas com os diferentes tipos de milho. Com isso, a diferença numérica entre a EMA dos dois tipos de milho passou a ser significativa quando foram feitas as correções pelo balanço de nitrogênio para o cálculo da EMAn.

Plavnik e Sklan (1995) observaram aumento significativo nos valores de EMA das dietas à base de milho submetidas à extrusão ou expansão. Porém, quando foram feitas as correções para obter os valores de EMAn, observaram diferenças significativas apenas entre os valores obtidos para a dieta submetida ao processo de extrusão em relação à dieta nãoprocessada, sendo esse fato atribuído às variações no balanço de nitrogênio das aves alimentadas com as diferentes dietas.

Os valores de EMAn do MNP foram próximos aos obtidos por Menten et al. (2002), que determinaram valores de $3.566 \mathrm{kcal} / \mathrm{kg}$ de MS e $3.213 \mathrm{kcal} / \mathrm{kg}$ de $\mathrm{MN}$ para o milho nãoprocessado com pintos na primeira semana. Assim como os resultados obtidos por esses autores, os valores determinados nesta pesquisa foram inferiores aos relacionados pelo Nutrient... (1994) e por Rostagno et al. (2000). Isso evidencia a necessidade de considerar diferentes valores de EMAn dos alimentos para formular rações para pintos e aves adultas.

Os resultados de desempenho dos frangos de corte são apresentados na Tab. 6, e os resultados da análise estatística, na Tab. 7.

Tabela 6. Desempenho de frangos de corte, alimentados com rações pré-inicial contendo milho processado pelo calor (MP) ou não (MNP)

\begin{tabular}{lccc}
\hline Tratamento & $\begin{array}{c}\text { Consumo } \\
\text { (g/ave) }\end{array}$ & $\begin{array}{c}\text { Ganho de peso } \\
\text { (g/ave) }\end{array}$ & $\begin{array}{c}\text { Conversão } \\
\text { alimentar }\end{array}$ \\
\hline T1 - Dieta com MNP & 1 a 7 dias de idade & 114 & 1,13 \\
T2 - Dieta com MP & 129 & 113 & 1,19 \\
T3 - Substituição isométrica T1 (MNP por MP) & 134 & 114 & 1,15 \\
CV(\%) & 132 & 2,81 & 2,58 \\
T1 - Dieta com MNP & 2,79 & 798 & 1,38 \\
T2 - Dieta com MP & 1 a 21 dias de idade & 783 & 1,43 \\
T3 - Substituição isométrica T1 (MNP por MP) & 1.100 & 813 & 1,37 \\
CV(\%) & 1.118 & 2,62 & 1,86 \\
T1 - Dieta com MNP & 1.114 & & 1,77 \\
T2 - Dieta com MP & 1,87 & 2.436 & 1,75 \\
T3 - Substituição isométrica T1 (MNP por MP) & 42 dias de idade & 2.454 & 1,77 \\
CV(\%) & 4.292 & 2.433 & 2,55 \\
\hline
\end{tabular}


Tabela 7. Médias de cada contraste (C) e níveis de significância para as variáveis de desempenho

\begin{tabular}{|c|c|c|c|}
\hline Contrastes & Consumo (g/ave) & Ganho de peso (g/ave) & Conversão alimentar \\
\hline \multicolumn{4}{|c|}{1 a 7 dias de idade } \\
\hline $\mathrm{C} 1=\mathrm{T} 1$ vs $\mathrm{T} 2$ & 129 vs $134(*)$ & 114 vs 113 (ns) & 1,13 vs $1,19(* *)$ \\
\hline $\mathrm{C} 2=\mathrm{T} 1$ vs $\mathrm{T} 3$ & 129 vs 132 (ns) & 114 vs 114 (ns) & 1,13 vs 1,15 (ns) \\
\hline \multicolumn{4}{|c|}{1 a 21 dias de idade } \\
\hline $\mathrm{C} 1=\mathrm{T} 1$ vs $\mathrm{T} 2$ & ns & $\mathrm{ns}$ & 1,38 vs $1,43(* *)$ \\
\hline $\mathrm{C} 2=\mathrm{T} 1 \mathrm{vs} \mathrm{T} 3$ & ns & ns & ns \\
\hline \multicolumn{4}{|c|}{1 a 42 dias de idade } \\
\hline $\mathrm{C} 1=\mathrm{T} 1 \mathrm{vs} \mathrm{T} 2$ & ns & ns & ns \\
\hline $\mathrm{C} 2=\mathrm{T} 1$ vs $\mathrm{T} 3$ & ns & ns & $\mathrm{ns}$ \\
\hline
\end{tabular}

ns= não significativo; $*(\mathrm{P}<0,05) ; * *(\mathrm{P}<0,01)$.

$\mathrm{T} 1=$ dieta com milho não processado; $\mathrm{T} 2=$ dieta com milho processado; $\mathrm{T} 3=$ dieta $\mathrm{T} 1 \mathrm{com}$ substituição isométrica.

Na primeira semana, a análise de contrastes $(\mathrm{C} 1)$ mostrou que as aves alimentadas com MP (T2) tiveram maior consumo e pior conversão alimentar em relação às que receberam MNP (T1). Como as rações foram formuladas para serem isonutritivas, esperava-se que os resultados não diferissem entre os tratamentos.

A ração formulada com MNP continha cerca de $1 \%$ a mais de óleo que a ração formulada com MP (Tab. 1), pois o valor de EMAn desse milho foi cerca $100 \mathrm{kcal} / \mathrm{kg}$ de $\mathrm{MN}$ maior e resultou em menor inclusão de óleo para atingir o nível de energia desejado. Dessa forma, os resultados obtidos para as aves alimentadas com MNP podem ser atribuídos, em parte, aos benefícios promovidos pela maior inclusão de gordura nas rações das aves. A melhora no desempenho das aves, associada à suplementação de gordura na ração, pode ser atribuída ao aumento da densidade calórica, ao efeito extracalórico que consiste no aumento da disponibilidade dos nutrientes dos ingredientes da ração e ao efeito extrametabólico das gorduras que resulta em uma melhoria da eficiência energética pelo aumento da energia líquida da ração.

A substituição isométrica (T3) do MNP por MP resultou em desempenho similar ao obtido com o milho MNP (T1) de acordo com o contraste 2. Como essas rações diferiam apenas no tipo de milho, esses resultados indicam que a diferença energética determinada anteriormente no ensaio de metabolismo entre os tipos de milho não foi suficiente para que ocorressem diferenças no desempenho das aves.

Os resultados são semelhantes aos relatados por Plavnik e Sklan (1995). De acordo com esses pesquisadores, embora o processamento térmico tenha melhorado, os valores de EMA e EMAn das rações à base de milho, o consumo de ração e o ganho de peso diário das aves alimentadas com rações processadas termicamente não diferiram significativamente do consumo e ganho de peso das aves alimentadas com a mesma ração sem processamento.

Para atingir o nível de energia pretendido na ração formulada com o valor de EMAn determinado para o MNP (T1), foi necessária a inclusão de mais de $4 \%$ de óleo de soja degomado. Conforme foi mostrado (Tab. 6), as aves alimentadas com essa ração apresentaram o melhor resultado de conversão alimentar. Dessa forma, a adição de óleo na ração pré-inicial teve efeito semelhante ao obtido para aves com idades mais avançadas, discordando, em parte, de Toledo et al. (2001), os quais afirmaram que a utilização de óleo ou gorduras nas rações préiniciais em níveis acima de $3 \%$ não tem boa eficácia sobre o desempenho das aves.

$\mathrm{Na}$ fase inicial total (1 a 21 dias), os tratamentos não influenciaram o ganho de peso e o consumo de ração. Entretanto, para a conversão alimentar, observou-se que aves alimentadas com a ração contendo MP (T2) apresentaram pior conversão alimentar em relação às que receberam ração com MNP (T1). Como as aves de todos os tratamentos receberam o mesmo tipo de ração após sete dias de idade, esse resultado pode ser decorrente dos resultados observados na primeira semana.

$\mathrm{Na}$ fase total de criação (1 a 42 dias), os tratamentos não influenciaram nas variáveis estudadas, indicando que os resultados da primeira semana não se mantiveram até a idade de abate. 
Esses resultados indicam que efeitos da dieta pré-inicial sobre o desempenho das aves na primeira semana de vida podem permanecer até o final da fase inicial (21 dias de idade) e desaparecer com o decorrer do ciclo de criação, não havendo, portanto, diferenças significativas no desempenho quando se avalia o ciclo total de criação (1 a 42 dias de idade). De acordo com Noy e Sklan (2002), quando todas as aves recebem o mesmo padrão de alimentação após a fase pré-inicial, os efeitos da dieta observados nessa fase desaparecem com o decorrer da idade. Dessa forma, segundo os autores, os efeitos sobre o crescimento das aves na fase pré-inicial, promovidos pelas alterações nas dietas, não são irreversíveis.

\section{CONCLUSÕES}

O processamento térmico não melhora o valor nutricional do milho. Dessa forma, a substituição do milho comum por milho processado, nessas condições, não melhora o desempenho dos frangos na fase pré-inicial.

\section{REFERÊNCIAS BIBLIOGRÁFICAS}

HOLAY, S.H.; HARPER, J.M. Influence of the extrusion shear environmental on plant protein texturization. J. Food Sci., v.47, p.1869 - 1874. 1982.

LEESON, S.; SUMMERS, J.D. Commercial poultry nutrition. 2.ed. Guelph: University Books, 1997. 355p.

MATTERSON, L.D.; POTTER, L.M.; STUTZ, N.W. et al. The metabolizable energy of feed ingredients for chickens. Storrs: The University of Connecticut, Agricultural Experiment Station, 1965. 11p. (Research Report, 7).

MENTEN, J.F.M.; LONGO, F.A.; PEDROSO, A.A. et al. Valores de energia metabolizável de milho e farelo de soja para frangos de corte na fase pré-inicial. In. REUNIÃO ANUAL DA SOCIEDADE BRASILEIRA DE ZOOTECNIA, 39., 2002, Recife. Anais... Recife: SBZ, 2002. 1 CD-Rom

MOREIRA, I.; OLIVEIRA, G.C.; FURLAN, A.C. et al. Utilização da farinha pré-gelatinizada de milho na alimentação de leitões na fase de creche: digestibilidade e desempenho. Rev. Bras. Zootec., v.30, p.440-448, 2001.
MOREIRA, I.; ROSTAGNO, H.S.; TAFURI, M.L. et al. Uso de milho processado a calor na alimentação de leitões. Rev. Soc. Bras. Zootec., v.23, p.412-421, 1994.

NIR, I. Mecanismos de digestão e absorção de nutrientes durante a primeira semana. In: CONFERÊNCIA APINCO DE CIÊNCIAS E TECNOLOGIA AVÍCOLA, 1998, Campinas. Anais... Campinas: FACTA, 1998. p.81-91.

NOY, Y.; SKLAN, D. Nutrient use in chicks during the first week posthatch. Poult. Sci., v.81, p.391-399, 2002.

NUTRIENT requirements of poultry. 9.ed. Washington DC: National Academy, 1994. 155p.

PENZ, A.M. Recentes avanços na nutrição de frangos de corte. In: ENCONTRO TÉCNICO SOBRE AVICULTURA DE CORTE DA REGIÃO DE DESCALVADO, 5., 2001, Descalvado. Anais... Descalvado:ACFD, 2001. p.15-46.

PEREIRA, J.R.A., ROSSI, P. Manual prático de avaliação nutricional de alimentos. Piracicaba: ESALQ, 1995. 25p.

PLAVNIK, I.; SKLAN, D. Nutritional effects of expansion and short time extrusion on feeds for broilers. Anim. Feed Sci. Technol., v.55, p.247251,1995 .

ROSTAGNO, H.S.; ALBINO, L.F.T.; DONZELE, J.L. et al. Tabelas brasileiras para aves e suínos: composição de alimentos e exigências nutricionais. Viçosa: UFV, 2000. 141p.

SILVA, D.J. Análise de alimentos: métodos químicos e biológicos. 2.ed. Viçosa:UFV, 1990. 165p.

TABELAS de composição química e valores energéticos de alimentos para suínos e aves. Concórdia: EMBRAPA-CNPSA, 1991. 97p. (Documento, 19).

TOLEDO, R. S.; VARGAS Jr, J.G.; ALBINO, L.F.T. et al. Aspectos práticos da nutrição pós-eclosão: níveis nutricionais utilizados, tipos de ingredientes $\mathrm{e}$ granulometria da dieta. In: CONFERÊNCIA APINCO DE CIÊNCIA E TECNOLOGIA AVÍCOLAS, 2001, Campinas. Anais... Campinas: FACTA, 2001. p.153167.

USER'S guide: statistics. Version 6.11. Cary, NC: SAS Institute, 1996. 842p.

VIEIRA, S.L.; POPHAL, S. Nutrição pós eclosão de frangos de corte. Rev. Bras. Ciênc. Avíc., v.2, p.189199,2000 